
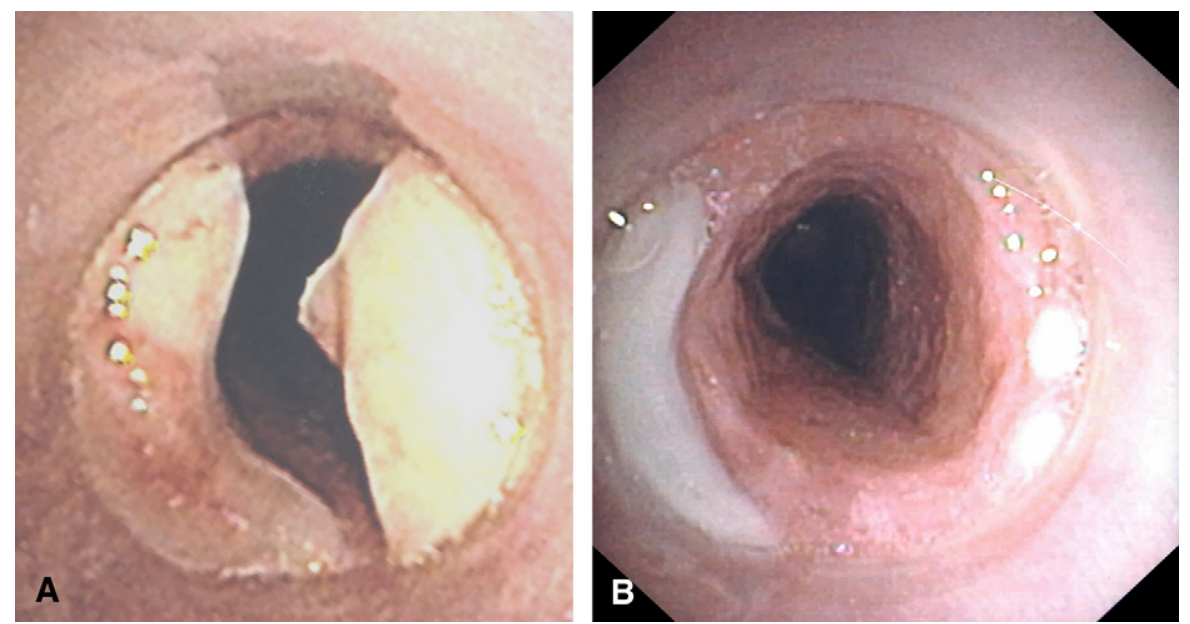

Figure 2. Granulation tissue seen over the distal end of the Y-stent at the left bronchial arm 1 week after placement (A) and 3 months after the commencement of steroid treatment (B).

surgery. Although resection remains the cornerstone of management and infection should always be excluded in the first instance, we suggest that systemic steroids be considered as an adjunct in intractable cases of foreign body granuloma.

\section{References}

1. Oey IF, Jeyapalan K, Entwisle JJ, Waller DA. Pseudo-tumours of the lung after lung volume reduction surgery. Ann Thorac Surg. 2004;77: 1094-6.
2. Dumon JF, Cavaliere S, Diaz-Jimenez JP, et al. Seven year experience with the Dumon prosthesis. J Bronchol. 1996;3:6-10.

3. Hocwald E, Sichel JY, Dano I, Meir K, Eliashar R. Adverse reaction to surgical sutures in thyroid surgery. Head Neck. 2003;25: 77-81.

4. Baughman RP, Lower EE, du Bois RM. Sarcoidosis. Lancet. 2003;361: 1111-8.

5. MacEwen C, Gregson R. Complications of strabismus surgery: how to avoid and manage them. In: Manual of strabismus surgery. Oxford: Butterworth-Heinemann; 2003. p. 181.

\title{
Teratoma with malignant transformation in the anterior mediastinum
}

Katsuhiko Shimizu, MD, PhD, ${ }^{\text {a }}$ Masao Nakata, MD, PhD, ${ }^{\text {a } Y u j i ~ H i r a m i, ~ M D, ~ P h D, ~}{ }^{\text {a }}$ Takashi Akiyama, MD, PhD, and Kazuo Tanemoto, MD, PhD, ${ }^{a}$ Kurashiki, Japan

M alignant transformation of teratoma in the mediastinum is rare. Pathologically, malignant teratoma can be divided into three types: immature teratoma, teratoma with other malignant germ cell tumor components (such as yolk sac tumor, embryonal carcinoma, choriocarcinoma, and seminoma), and teratoma with malignant

From the Division of Thoracic and Cardiovascular Surgery, Department of Surgery, ${ }^{\mathrm{a}}$ and the Division of Pathology, ${ }^{\mathrm{b}}$ Kawasaki Medical School, Kurashiki, Japan.

Received for publication Oct 26, 2007; revisions received Jan 4, 2008; accepted for publication Jan 6, 2008.

Address for reprints: Katsuhiko Shimizu, 577 Matsushima, Kurashiki, Okayama 701-0192, Japan (E-mail: kshimizu@med.kawasaki-m.ac.jp).

J Thorac Cardiovasc Surg 2008;136:225-7

0022-5223/ $\$ 34.00$

Copyright $@ 2008$ by The American Association for Thoracic Surgery doi:10.1016/j.jtcvs.2008.01.030 transformation (TMT). ${ }^{1,2}$ TMT is a non-germ cell malignant tumor arising from a preexisting mature teratoma. To our knowledge of the literature, TMT in the mediastinum is extremely rare. ${ }^{3,4}$ This report describes a surgical case of adenocarcinoma arising from a mature, cystic teratoma in the anterior mediastinum.

\section{Clinical Summary}

A 43-year-old woman was admitted to the hospital with a mediastinal mass. Eight years previously, she had undergone a medical workup for this mediastinal mass but had refused to heed the recommendation of surgery. At this later admission, she reported a 3month history of exertional breathlessness. Chest radiography showed a large mass shadow from the mediastinum to the left thoracic cavity; the mass had clearly enlarged relative to its appearance 8 years previously. Contrast-enhanced computed tomography showed a lobulated, cystic mass with a fat component that measured $12 \times 9 \times 14 \mathrm{~cm}$ in the anterior mediastinum to the left thoracic cavity (Figure 1). The laboratory values were within reference limits. Human chorionic gonadotropin, $\alpha$-fetoprotein, and 


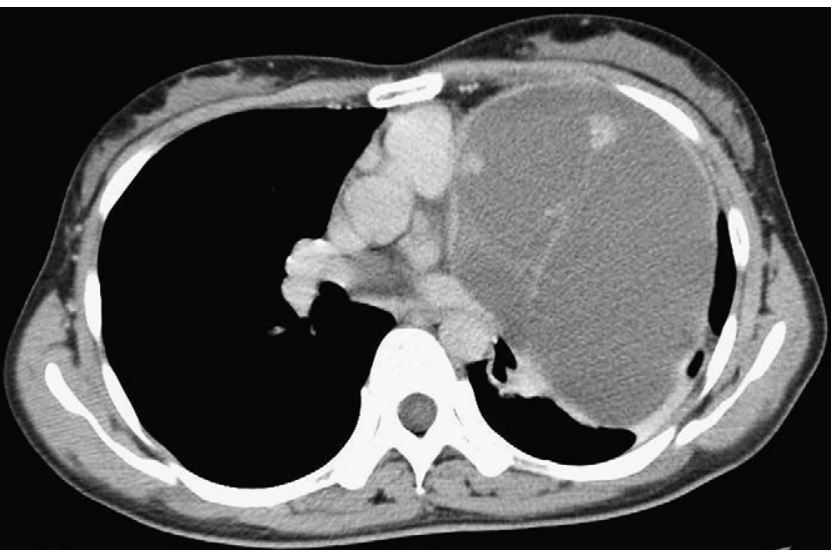

Figure 1. Contrast-enhanced computed tomographic scan showing lobulated, low-attenuated mass containing fat component in anterior mediastinum.

carcinoembryonic antigen levels were within acceptable limits, but carbohydrate antigen 19-9 level was high $(707 \mathrm{U} / \mathrm{mL})$.

Thoracotomy was performed in July 2007. The tumor, which was located on the anterior mediastinum and the left thoracic cavity and had not invaded the left lung and pericardial sac, was completely excised. The resected tumor was $12 \times 9 \times 17 \mathrm{~cm}$ in size and $820 \mathrm{~g}$ in weight. The cut surface revealed a multilocular cyst containing yellowish brown material. The wall of the cyst was 3 to $5 \mathrm{~mm}$ in thickness, and a small, pale gray, solid area protruded in part of interior surface of the cyst (Figure 2, A). Microscopically, although most of the mass was a mature cystic teratoma with necrosis, the solid portion of the wall $(18 \times 8 \mathrm{~mm})$ was found to be moderately differentiated adenocarcinoma (Figure 2, $B$ ). No bone or cartilage tissues were observed, however, and there were no immature teratomatous elements or other germ cell components. The final histologic diagnosis was cystic teratoma with somatic-type malignancy (adenocarcinoma). The patient had an uneventful postoperative course. She has not received adjuvant chemotherapy or radiotherapy and is alive without recurrence 6 months after the surgery.

\section{Discussion}

Teratoma is commonly found both in gonadal organs and at extragonadal sites such as the mediastinal, sacrococcygeal, and pineal regions. TMT is rarely found in any organ, but it is sometimes found in the ovary. According to the literature, malignant transformation occurs in $1 \%$ to $2 \%$ of ovarian dermoid cysts. ${ }^{5}$ TMTs are seen more frequently than benign teratomas in older patients, and the malignant transformation involves one of the epithelial elements. The most frequent histologic type is squamous cell carcinoma (75\%), followed by adenocarcinoma and carcinoid. On the other hand, little is known about the general incidence and pathologic features of TMT in the mediastinum.

TMT has been classified into two clinical and pathologic types: TMT induced by chemotherapy or irradiation and naturally occurring TMT. ${ }^{3}$ Almost all cases of TMT are of the former type, and they tend to occur in young patients with an initial presentation
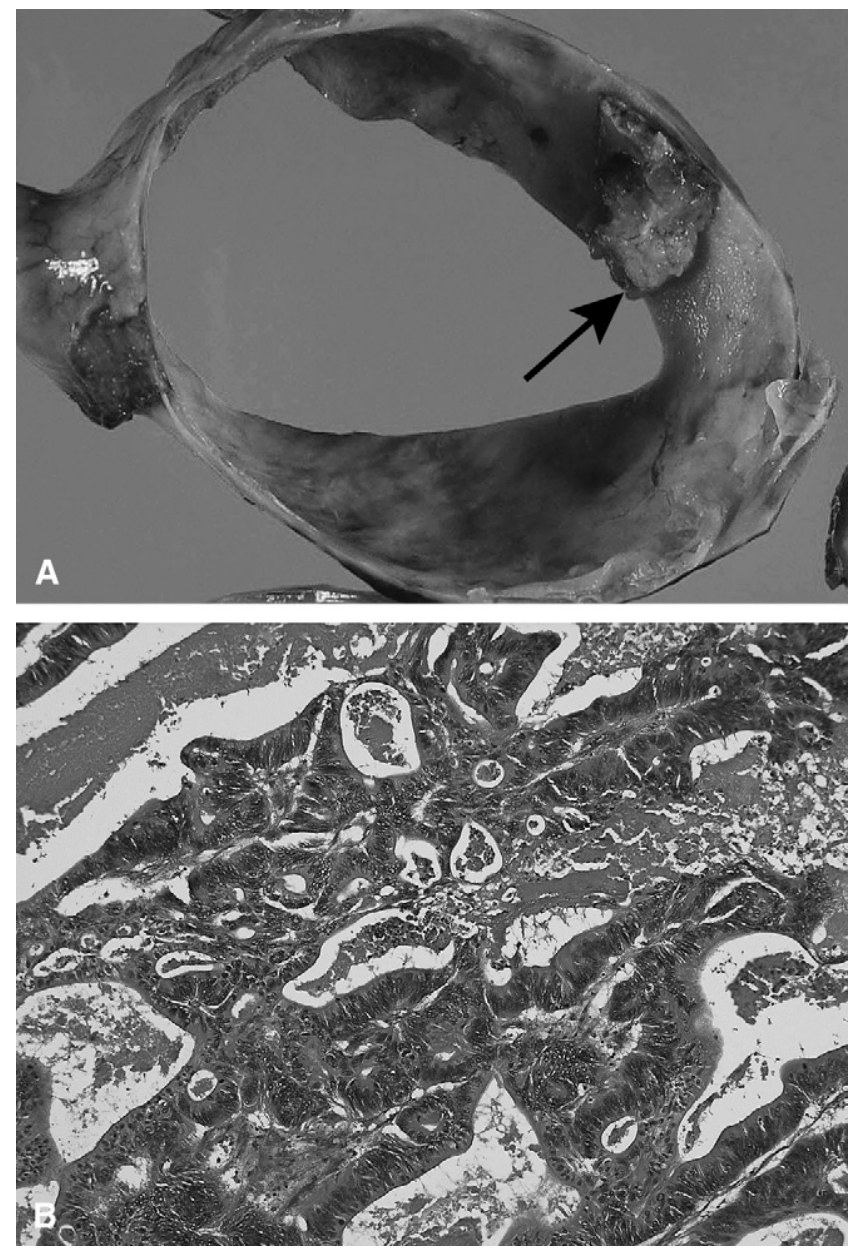

Figure 2. A, Macroscopic features of resected tumor. Small, pale gray, solid area (arrow) protrudes in part of interior surface of cyst. B, Microscopic examination of medial part of mass, in which moderately differentiated adenocarcinoma crosses fibrous outer wall (original magnification $10 \times$, hematoxylin-eosin stain).

of a malignant germ cell tumor. The latter type has rarely been reported. In a review of the literature, naturally occurring TMT was described in only two reports. Morinaga and colleagues ${ }^{3}$ described a case of TMT with well-differentiated adenocarcinoma, and Jung and associates ${ }^{4}$ described a case of TMT with poorly differentiated adenocarcinoma. Characteristically, naturally occurring TMT is seen in a mature teratoma of long duration. In our case, the patient had a long history of tumor ( $>8$ years) with no treatment, thus suggesting that malignant transformation may have occurred in a preexisting mature teratoma without any effect of chemotherapy or irradiation. The effect of adjuvant therapy on TMT is uncertain. In this case, we considered adjuvant therapy unnecessary, because the tumor was completely excised and there is no evidence for the benefits of chemotherapy for this rare tumor.

In summary, this report documents a case of TMT (adenocarcinoma) in the anterior mediastinum. Naturally occurring TMT in the 
mediastinum is extremely rare, and the risk of malignant transformation may be increased with a long-standing, mature teratoma.

\section{References}

1. Ulbright TM, Loehrer PJ, Roth LM, Einhorn LH, Williams SD, Clark SA. The development of non-germ cell malignancies within germ cell tumors. A clinicopathologic study of 11 cases. Cancer. 1984;54:1824-33.

2. Ahmed T, Bosl GJ, Hajdu SI. Teratoma with malignant transformation in germ cell tumors in men. Cancer. 1985;56:860-3.
3. Morinaga S, Nomori H, Kobayashi R, Atsumi Y. Well-differentiated adenocarcinoma arising from mature cystic teratoma of the mediastinum (teratoma with malignant transformation): report of a surgical case. $A m$ J Clin Pathol. 1994;101:531-4.

4. Jung JI, Park SH, Park JG, Lee SH, Lee KY, Hahn ST. Teratoma with malignant transformation in the anterior mediastinum: a case report. Korean J Radiol. 2000;1:162-4.

5. Chadha S, Schaberg A. Malignant transformation in benign cystic teratomas: dermoids of the ovary. Eur J Obstet Gynecol Reprod Biol. 1988; 19:329-38.

\title{
Carcinoid tumor nested within a bronchogenic cyst
}

\author{
Elliot Servais, MD, Subroto Paul, MD, Jeffrey L. Port, MD, Nasser K. Altorki, MD, and Paul C. Lee, MD, New York, NY
}

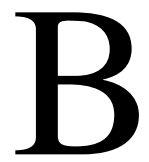

ronchogenic cysts are congenital lesions of the embryonic foregut. First described in 1859 by Meyer, ${ }^{1}$ these anomalies are believed to arise from supernumerary or abnormal budding of the tracheobronchial tree. These cysts, which often remain asymptomatic, are brought to clinical attention after incidental discovery on chest radiography or owing to complications such as infection, compression, and, rarely, hemorrhage or rupture. However, a less widely recognized phenomenon is occult neoplastic disease within the cyst wall. Herein, we describe a case of a carcinoid tumor within the wall of a resected bronchogenic cyst.

\section{Clinical Summary}

A 54-year-old woman had shortness of breath and chest tightness for 5 weeks. She reported a history of hypertension, mitral valve prolapse, and basal cell carcinoma of the right thigh. She had a 15 pack-year smoking history but had quit 5 weeks earlier. Results of the physical examination were unremarkable, with no cardiopulmonary abnormalities. Subsequent workup with a chest radiograph demonstrated a mediastinal mass. Concomitant chest computerized tomography $(\mathrm{CT})$ scan showed a $5.8 \times 5.8$-cm cystic mass in the superior middle mediastinum (Figure $1, A$ ). Subsequent chest magnetic resonance imaging (MRI) confirmed the cystic nature of the

From the Division of Thoracic Surgery, Department of Cardiothoracic Surgery, New York Presbyterian Hospital, Weill Medical College of Cornell University, New York, NY.

Received for publication Dec 9, 2007; accepted for publication Feb 5, 2008.

Address for reprints: Paul C. Lee, MD, Division of Thoracic Surgery, Department of Cardiothoracic Surgery, New York Presbyterian Hospital, Medical College of Cornell University, New York, New York 10021 (E-mail: pc19001@med.cornell.edu).

J Thorac Cardiovasc Surg 2008;136:227-8

$0022-5223 / \$ 34.00$

Copyright (C) 2008 by The American Association for Thoracic Surgery doi:10.1016/j.jtcvs.2008.02.042 mass with T2-weighted images demonstrating the cyst to be fluid filled as suspected on chest CT. Chest MRI did not reveal any communication with the esophagus (Figure $1, B$ ). These findings were consistent with a diagnosis of bronchogenic cyst.

The patient was taken to the operating room where a right thoracotomy was performed. Exploration revealed the cystic mass to be adherent to the trachea with surrounding inflammation and scar tissue. The cystic mass was freed from the trachea and surrounding mediastinal tissue. Resection was facilitated after aspiration of the cyst's fluid contents. Postoperatively, she had an uncomplicated course and was discharged from the hospital on postoperative day 4 . Subsequent pathologic evaluation of the specimen revealed a bronchogenic cyst with typical carcinoid tumor nested within the cyst wall (Figure 1,C and $D$ ). The patient remains well 3 months postoperatively and will undergo no further treatments for carcinoid other than periodic surveillance.

\section{Discussion}

Bronchogenic cysts are the most common cystic lesions of the mediastinum. The incidence of symptoms varies from $30 \%$ to $70 \%{ }^{2}$ occurring most commonly owing to infectious or compressive causes. It has become standard management to resect symptomatic bronchogenic cysts. More important, perhaps, is the widely accepted policy of resection for incidentally discovered, asymptomatic cysts as well.

A retrospective review in 1996 by Ribet, Copin, and Gosselin ${ }^{3}$ supported the notion of resection for asymptomatic disease, suggesting that late complications outweigh the "acceptable morbidity" of resection. Malignant transformation of the cyst wall has also been described. Case reports have demonstrated squamous cell carcinoma, adenocarcinoma, and leiomyosarcoma arising from the bronchogenic cyst wall. ${ }^{2}$ In this report, we describe a case of carcinoid tumor occurring within the wall of a bronchogenic cyst. This is the second case of its kind reported in the English literature - the first was described by Greenfield and Howe ${ }^{4}$ in 1965.

Bronchial carcinoids fall within a spectrum of pulmonary neuroendocrine tumors ranging from typical carcinoid, characterized by an 